\title{
La biblioteca pública como institución política: la correlación entre bibliotecario público y bibliotecario político
}

\author{
Felipe Meneses-Tello \\ Universidad Nacional Autónoma de México, Facultad de Filosofía y Letras, México, México \\ fmeneses001@yahoo.com.mx
}

\section{DOI: https://doi.org/10.26512/rici.v12.n3.2019.24669}

Recebido/Recibido/Received: 2019-05-14

Aceitado/Aceptado/Accepted: 2019-08-23

Resumen: El autor investiga acerca de la conexión que existe entre "bibliotecología y política», considerando en este caso la literatura especializada que ha estado cultivando el nexo «bibliotecas y política». Asimismo, determina correlativamente el concepto de «biblioteconomía política» con base en un conjunto de ideas, premisas que de manera habitual han pasado inadvertidas en la percepción teórica que se imparte en las escuelas de bibliotecología, biblioteconomía y ciencias de la información, o que han sido subvaloradas o ignoradas en la esfera de la práctica bibliotecaria. También explica el influjo de la práctica política, en contraste con la práctica bibliotecaria, en el universo de las bibliotecas públicas. Plantea discernimientos que fundamentan la esfera política del personal que labora en este tipo de centros bibliotecarios, en el marco precisamente de una sociedad política. La formulación de perfiles que sustentan la relación entre «bibliotecas y política» la considera de extrema importancia porque, a pesar de que vivimos en determinados contextos políticos durante toda la vida, se sigue privilegiando, teórica y prácticamente, el dogma ortodoxo que por tradición ha estado separando o rechazando la política en el contexto de la administración bibliotecaria. El contenido, de esta manera, gira en torno a la naturaleza política de la biblioteca pública, con la finalidad de que el bibliotecario público del siglo XXI asuma la responsabilidad de cultivar una clara praxis política (reflexión y acción). En este orden de ideas, se analiza y define el concepto de «bibliotecario político».

Palabras clave: Biblioteca pública. Bibliotecario público. Bibliotecario político. Biblioteconomía política. Política.

\section{A biblioteca pública como instituição política: a correlação entre bibliotecário público e bibliotecário político}

Resumo: O autor investiga sobre a conexão que existe entre «biblioteconomia e política», considerando neste caso a literatura especializada que tem cultivado o nexo "bibliotecas e política". Da mesma forma, o conceito de "biblioteconomia política» é determinado correlativamente com base em um conjunto de ideias, premissas que tradicionalmente passaram despercebidas na percepção teórica que é ensinada nas escolas de biblioteconomia e ciências da informação, ou que eles foram desvalorizados ou ignorados na esfera da prática bibliotecária. Também explica a influência da prática política, em contraste com a prática bibliotecária, no universo das bibliotecas públicas. Delineia discernimentos que fundamentam a esfera política do pessoal que trabalha neste tipo de centros bibliotecários, precisamente no contexto de uma sociedade política. A formulação de perfis que sustentam a relação entre «bibliotecas e política» é 
considerada de extrema importância, pois, embora vivamos em determinados contextos políticos ao longo de nossas vidas, ainda privilegiamos, teoricamente e praticamente, o dogma ortodoxo que tem estado tradicionalmente separando ou rejeitando a política no contexto da administração da biblioteca. O conteúdo, dessa maneira, gira em torno da natureza política da biblioteca pública, com o objetivo de que o bibliotecário público do século XXI assuma a responsabilidade de cultivar uma clara práxis política (reflexão e ação). Nesta ordem de ideias, o conceito de «bibliotecário político» é analisado e definido.

Palavras-chave: Biblioteca Pública. Bibliotecário de biblioteca pública. Bibliotecário político. Biblioteconomia política. Política.

\section{Public library as a political institution: the correlation between public librarian and political librarian}

Abstract: The author investigates the connection that exists between "library science and politics», considering in this case the specialized literature that has been cultivating the nexus "libraries and politics». Likewise, the concept of "political librarianship" is determined correlatively based on a set of ideas, premises that have traditionally gone unnoticed in the theoretical perception that is taught in the schools of library science, librarianship and information sciences, or that have been undervalued or ignored in the sphere of library practice. The influence of political practice, opposed to the practice of librarianship, is also explained within the public library context. The ideas underlying the political sphere of the personnel that work in this kind of library, within the framework of a political society, are presented. The formulation of profiles that sustain the relationship between "libraries and politics" is considered extremely important because although we experience certain political contexts throughout our lives, we continue to privilege, theoretically and practically, the orthodox dogma that has traditionally resulted in the separation or rejection politics in the context of library administration. As a result, public librarian of the $21^{\text {st }}$ century must assume the responsibility for cultivating a clear political praxis (reflection and action), when it comes to content that resolves around the political nature of the public library. In this order of ideas, the concept of "political librarian" is analysed and defined.

Keywords: Public Library. Public librarian. Political librarian. Political librarianship. Polítics.

\section{Introducción}

Tanto en el mundo de la práctica como de la teoría se observa la compleja relación que existe entre «bibliotecas y política». En el marco de esta unidad conceptual se ha estado intentando, a partir del siglo XX, plantear ideas en donde las bibliotecas públicas ocupan un lugar preponderante en la compleja esfera de la política. De tal modo que la política como actividad y como ciencia nos permite ampliar y profundizar el panorama orgánico-funcional de las bibliotecas en general y las bibliotecas públicas en particular. Así, la política es la actividad humana de la que nada ni nadie puede evitar o eludir. En este sentido, las bibliotecas y su personal bibliotecario no están al margen del quehacer ordenado de la política que apunta hacia el bien común, que afianza el interés general y que garantiza la convivencia colectiva. Pensar la política positivamente entraña entonces distinguir, por ejemplo, sus perspectivas ética, cívica, ciudadana, democrática, gubernativa y estatal. Este punto de vista se asocia a la idea que afirma, desde la perspectiva de la biblioteconomía progresista: "La política debe ser una práctica racionalmente orientada hacia la construcción y el mantenimiento del bien común" (SILVA, 
2018, p. 210). Es decir, si “la política trata de la búsqueda de la felicidad pública o del gusto por la libertad pública" (PHILLIPS, 1996, p. 54), este estado de ánimo positivo, como un componente de bienestar social, debe considerarse un bien público. De ser así, entonces las bibliotecas y sus bibliotecarios tienen el compromiso de colaborar para lograr el ideal democrático-republicano del bien común.

El «poder público» es una noción central en la praxis (pensamiento y acción) de la política; es el objeto común de estudio de la ciencia política. En el marco de los problemas teóricos de la política moderna es posible pensar en un conjunto de conceptos fundamentales, como los que plantea el profesor italiano Umberto Cerroni (1997): método, teorías, procesos, sujetos, instituciones y categorías. En cada uno de estos planos conceptuales es posible identificar nociones teóricas en relación con el objeto institucional de estudio de la biblioteconomía pública: la biblioteca pública como institución social que forma parte de los servicios públicos que por compromiso de política pública el Estado debe garantizar al pueblo. Es por esto que la ciencia política es, sin duda, de gran utilidad para la investigación en biblioteconomía (ROBBINS-CARTER, 1984, p. 425).

Así, desde una perspectiva crítica algunos profesionales de la bibliotecología observamos con toda claridad que "la política está en todas partes" en donde se desarrolla el quehacer bibliotecario; a pesar de esto, "la política se considera una mala palabra y se la trata con cierto desdén" (SMITH, 2009, p. xxix) o indiferencia, principalmente en aquellos contextos en que se desenvuelven los diferentes grupos del gremio bibliotecario tradicional. Pensar que el buen bibliotecario es aquel que evita, desprecia o ignora la política y que, por tanto, se mantiene alejado de todo lo que implica hacer política y ser político, significa seguir defendiendo una idea anacrónica y falaz.

Analizar la relación que existe entre bibliotecología, biblioteconomía y política implica ir más allá del modelo que sostiene el perfil del bibliotecario como agente público (MACHADO, JUNIOR y ACHILLES, 2014), para así formular el paradigma del bibliotecario como funcionario político en la esfera de las bibliotecas públicas. Este es el objetivo esencial de la presente investigación.

\section{Procedimiento metodológico}

Se trata de una investigación teórica, por tal motivo el discurso está basado, en primera instancia, en el método bibliográfico-documental. Para tal efecto, se realizó la búsqueda de literatura especializada en fuentes de referencia que mantienen servicio en línea de información científica. Entre ellas cabe mencionar las siguientes: Library Información Sciences Abstracts (LISA); Web of Science (en la que se incluye el Social Science Citation Index); Scopus, importante 
base datos de referencias y resúmenes de artículos de revistas, libros y memorias de conferencias. La búsqueda se extendió a varios catálogos electrónicos de relevantes sistemas bibliotecarios de América Latina y otras regiones del mundo. Por supuesto, también se utilizó Google Académico y la consulta directa a revistas especializadas en bibliotecología, biblioteconomía y ciencia de la información que están disponibles en acceso abierto en Internet. También se buscó literatura en las bibliografías referenciadas en los escritos publicados. En tanto, la búsqueda de información pertinente y relevante se hizo mediante un determinado rastreo conceptual, el cual consistió en detectar la combinación de palabras clave como: bibliotecología, biblioteconomía, bibliotecas públicas, bibliotecario público, política, político, democracia, república y otras nociones circundantes.

Tanto la literatura que se reseña en el rubro Bibliotecología y política como la que se cita a lo largo del discurso fue seleccionada teniendo en cuenta los siguientes criterios: 1] el importante conocimiento interrelacionado que contiene entre bibliotecología, biblioteconomía, bibliotecas, bibliotecarios y política; 2] la variedad, el rigor y los desafiantes puntos de vista que expresan los autores en torno a la articulación sobre estos temas; y 3 ] las coordenadas de tiempo y espacio en que han sido publicados estos libros y artículos. Así, se trata de una bibliografía sustancial que en suma pone en tela de juicio lo expuesto por la bibliotecología tradicional. Es decir, explica cosas que se han subestimado, omitido o ignorado en la teoría-práctica ortodoxa de esta disciplina.

El presente discurso gira en torno al paradigma que se observa, de lo general a lo particular, entre el nexo bibliotecología y política, la noción de biblioteconomía política y el concepto de bibliotecario público. El primer asunto se explica mediante la reseña de algunas obras que de manera elocuente tratan esta conexión; el segundo tema gravita en una serie de ideas o premisas que han escrito varios autores, las cuales permiten fundamentar, desde diferentes ópticas y de manera integral, el tema que nos ocupa; el tercer motivo se explica y define porque es una expresión que conduce a la valoración del concepto clave: el bibliotecario político. Con base en esto es como se detallan los siguientes apartados, a saber: la actividad técnica y la actividad política inherente a la comunidad de los bibliotecarios públicos; la naturaleza política de la biblioteca pública; la praxis política del bibliotecario público; y como corolario la conceptualización del bibliotecario político. En concordancia con esto, la estructura del presente trabajo refleja una estrategia de razonamientos que ha permitido no solamente exponer diferentes deducciones lógicas, sino que induce a continuar profundizando y ampliando esta naturaleza de asuntos. Es decir, el procedimiento metodológico del discurso se basa, asimismo, en ideas que parten del estudio y análisis de la temática aludida. 


\section{Bibliotecología y política}

El principal referente para distinguir este nexo, que a partir del siglo XX comenzó a generarse, es el pensamiento escrito, el discurso publicado en forma de artículos de revistas y monografías. Así, la literatura en bibliotecología es elocuente en su intento de relacionar las bibliotecas con la política (las actividades que se realizan mediante las políticas públicas para generar el bien común del pueblo) y lo político (la estructura del poder político que se constituye en Estado). Sin la intención de abordar el asunto de manera exhaustiva, es pertinente y relevante tener presente algunos autores que han cultivado el nexo «bibliotecas y política» en el campo de la bibliotecología (Library Science), en el que se incluye la biblioteconomía (librarianship).

Hace cerca de setenta años Oliver Garceau publicó su libro The public library in the political process (1949), "volumen seminal" que dada su naturaleza política es posible que sea el trabajo más citado en el campo de la biblioteconomía (ROBBINS-CARTER, 1984, p. 429), pues es tema que sigue vigente en la literatura de la especialidad. Un claro ejemplo en este sentido es el volumen 65, fascículo 2, (2016), de la revista Library Trends dedicado precisamente al asunto "Libraries in the political process». Entre los artículos publicados en esta fuente destaca el escrito del sociólogo Denis Merklen, quien a pregunta expresa: Is the library a political institution? asevera, con base en varios razonamientos, que "las bibliotecas son instituciones políticas dentro de contextos políticos diferentes"; que es posible "acercarnos a las bibliotecas como instituciones políticas dentro de sus respectivos contextos" (2016a: 145). Merklen (2016) también publicó el libro Bibliotecas en llamas: cuando las clases populares cuestionan la sociología y la política, obra que explica los motivos de fondo del por qué las clases subalternas han estado apedreando e incendiando varias bibliotecas públicas en diferentes barrios populares de Francia durante más de veinte años.

Otra obra representativa sobre el tema que nos ocupa es The politics of public librarianship, de David Shavit (1936-2017). A través de una lectura atenta podemos observar que el autor enfatiza, desde diferentes aristas, el carácter político de la biblioteca pública, del bibliotecario público y, consecuentemente, de la biblioteconomía pública. Shavit, oriundo de Israel y profesor de bibliotecología en la Northern Illinois University, afirmaría en ese libro, publicado en 1986, que a partir del estudio de Garceau la política de la biblioteconomía pública era todavía un área de investigación en gran parte inexplorada. Él fundamentaría este punto de vista al afirmar que en la fuente de referencia Library Literature aún no se incluía, hasta entonces, un tema sobre política y biblioteconomía (politics and librarianship). Entre otras cosas, Shavit estudia y analiza los aspectos políticos de la biblioteca pública para explicar que la biblioteconomía de carácter público está relacionada con la política. La esencia teórica que escribe este autor se sustenta en un marco de referencia inherente a los sistemas bibliotecarios 
estadounidenses, tal y como lo hizo también en otro de sus libros intitulado Federal aid and state library agencies: federal policy implementation (1985). No obstante el tiempo transcurrido, sus ideas conceptuales nos pueden seguir orientando para distinguir razonamientos sobre la temática y así continuar profundizando y ampliando este conocimiento, tal y como se intenta mediante este presente trabajo.

El libro Public libraries, public policies, and political processes, de Jaeger, Gorham, Bertot y Sarin, muestra un importante análisis entreverado del contexto político que rodea a las bibliotecas públicas estadounidenses. El término política se enfoca en relación con el impacto de los procesos y discursos políticos en torno a este tipo de instituciones bibliotecarias y no en "la promoción del respaldo activo de políticos o partidos políticos específicos por parte de las bibliotecas" (JAEGER, GORHAM, BERTOT y SARIN, 2014, p. 3). Se trata de hacer comprender el universo político de estas bibliotecas desde las complejas perspectivas de gobierno. De modo que los autores aseveran, como mensaje principal de este libro, que existe una necesidad apremiante de que el gremio bibliotecario público 1] esté consciente del proceso político y sus implicaciones en el universo de estos centros bibliotecarios; 2] esté en sintonía con las interrelaciones entre la política (politics) que realizan los poderes públicos que constituyen el sistema gubernamental y la política (policy) que refleja un plan general de reglas y principios que guían las decisiones en materia de políticas públicas; y 3] participe en el proceso de las políticas que apuntan a beneficiar las bibliotecas públicas y el bien de la comunidad (JAEGER, GORHAM, BERTOT y SARIN, 2014, p. 148).

Más aún, en 2015 comenzó a publicarse la revista The Political Librarian. Se trata de una nueva revista digital en acceso abierto, editada por la Washington University, en la que se destaca el cruce de temas sobre bibliotecas locales, política pública y política tributaria. En el segundo volumen Paul T. Jaeger y Lindsay C. Sarin (2016) publicaron un artículo con un título sumamente sugestivo: "All librarianship is political: educate accordingly» [Toda la biblioteconomía es política: educar en consecuencia]. Estos autores infieren en su artículo que aunque las bibliotecas como instituciones y las acciones de los profesionales de la biblioteca son inherentemente políticas, la educación estadounidense en bibliotecología no ha formado a los estudiantes en torno a esta disciplina para enfrentar el mundo político en el que viven. Esta misma situación coincide con los resultados en cuanto a la formación política del bibliotecario en Brasil (SPUDITS, MORAES y CORREA, 2016, p. 24). Si tenemos en cuenta los planes de estudios de las escuelas de bibliotecología, biblioteconomía y ciencia de la información en otras latitudes, esta realidad es posible que sea la misma en otros países, entre estos los de América Latina. Aunque para distinguir con claridad y certeza esta situación convendría realizar un estudio empírico al respecto. 
A pesar de lo anterior, el discurso latinoamericano en el presente siglo, concerniente a esta temática, no se ha quedado a la zaga si tomamos en cuenta algunos de los diferentes enfoques abordados por varios autores de esta región (QUIROGA, 2003; JARAMILLO, ÁLVAREZ y MONCADA, 2005; FÚSTER y LANGELÁN, 2010; MENESES, 2013, 2013a, 2014; BORNACELLY, QUINTERO y CUARTAS, 2014). Los escritos más recientes (ALBORNOZ, 2016; BERASA, 2016; CIVALLERO, 2016; OPORTO, 2016; PARADA, 2016; MENESES, 2017a) muestran un interesante calidoscopio referente a la relación «bibliotecas y política». La reflexión y el debate, el análisis y el estudio, la lectura del texto y del contexto, en relación con la praxis político-bibliotecaria, es la base teórico-práctica que nos permite distinguir, valorar y razonar la responsabilidad política del personal bibliotecario, particularmente la referente a la del bibliotecario público.

Formação e atuação política na biblioteconomia es el título del libro publicado más recientemente sobre la temática en Brasil. Como lo indica el título de esta obra, el conjunto de colaboraciones de diferentes autores demuestra que el uso del término política, en el campo de la biblioteconomía, se refiere solamente al hacer técnico de los bibliotecarios, pero no a la política como una dimensión de vida profesional del personal bibliotecario que se halla inserto en una sociedad política. Es decir, en este libro se tratan asuntos que versan sobre la dimensión política del área, el perfil de los bibliotecarios candidatos a las elecciones municipales, la participación de la mujer en la política, la actuación política de las entidades del gremio bibliotecario, los desafíos para la formación crítica y política de las bibliotecarias, la formación política de las bibliotecarias y las relaciones raciales, el pensamiento crítico en las culturas africanas y afrodescendientes en la Biblioteconomía, entre otros temas (SPUDEIT, PEREIRA, LOBÃO y DAVID, 2018, p. 12). Esta publicación es, sin duda, un aliciente para la comunidad bibliotecaria iberoamericana con el fin de emprender cambios en los planes de estudio, crear proyectos modelo de investigación y llevar a cabo inusitados programas de práctica bibliotecaria, en donde el fenómeno de la política permita articular una plataforma teóricapráctica para continuar construyendo los fundamentos concernientes al tema que nos ocupa.

Así, se puede afirmar que se ha estado reflexionando, desde diferentes ángulos, temas inherentes a la bibliotecología con la política en el terreno de la literatura especializada, pero no en el campo de la educación que se imparte para formar cuadros profesionales en materia de administración de instituciones bibliotecarias y de información (SPUDEIT, MORAES y CORRÊA, 2016; JAEGER y SARIN, 2016; MARTINS y FERREIRA, 2018; TAVARES, 2018). Si nos limitáramos a estudiar el nexo en cuestión, a partir del análisis de los planes de estudio que se transmiten en las escuelas de bibliotecología, biblioteconomía y ciencias de la información, no tendríamos los elementos necesarios para fundamentar que la teoría y la práctica de estas disciplinas están estrechamente relacionadas con el mundo de la política. Los autores que se han empeñado en 
explicar que el objeto institucional de estudio de la bibliotecología no se mantiene aislado de la teoría-práctica de la política, son quienes han estado cimentando un terreno firme para demostrar lo que en este sentido a menudo se omite en las aulas. Esta laguna educativa que se ha extendido hasta la práctica bibliotecaria, al mantener erróneamente el quehacer bibliotecario apartado de la teoría y práctica en materia política, se entiende mejor cuando se afirma:

\begin{abstract}
Hablar de formación política es caminar por temas como: democracia, gobierno, ideologías, partidos y elecciones, políticas públicas, ciudadanía y participación política, opinión pública. Formación política presupone comprender los conceptos de igualdad y desigualdad y cómo estos dos conceptos se articulan con las relaciones de clase, de género, de raza y etnia. Temas poco recurrentes en el campo de la Biblioteconomía y Ciencia de la Información en especial en los cursos de Biblioteconomía, Gestión de la Información y Documentación (MARTINS y FERREIRA, 2018, p. 81).
\end{abstract}

En concordancia con lo expresado, resulta razonable pensar en el concepto de bibliotecología política, del cual se deriva la categoría de biblioteconomía política, en torno de la que a continuación se diserta.

\title{
4 Biblioteconomía política
}

Si la biblioteconomía se desarrolla en un determinado contexto de política cultural, entonces esta disciplina colabora en el desenvolvimiento de la cultura política. Consecuentemente es apropiado pensar en temas referentes a la política cultural de la biblioteconomía (HARRIS, 2012), por un lado, y en la cultura política de la biblioteconomía, por el otro. A pesar de esto, la biblioteconomía tradicional no ha concebido relacionarse con la política. Por esto se tiene la idea que la biblioteca es una institución apolítica, que el personal bibliotecario debe serlo también. El punto de vista que afirma que: "La biblioteconomía como campo de actuación profesional situada en el área de conocimiento de las Ciencias Sociales Aplicadas se ha mantenido, a lo largo de las últimas décadas, distanciada del debate acerca de la política" (MARTINS y FERREIRA, 2018, p. 78), nos debe motivar para reflexionar y demostrar que el quehacer del personal de las bibliotecas públicas no está fuera o alejado del universo teórico y práctico de la política. En cierta manera esta problemática se deriva del déficit de conocimiento político que se suscita en el marco de la biblioteconomía como campo de enseñanza profesional. Por lo que es pertinente ir cultivando el perfil de una biblioteconomía política propiamente dicha, pues: "Si construir y operar una biblioteca es un acto inherentemente político y las bibliotecas están interactuando constantemente con el mundo político, entonces la educación bibliotecaria debe preparar a los futuros bibliotecarios para navegar con éxito en una profesión politizada" (JAEGER y SARIN, 2016, p. 24). 
Es claro que la biblioteconomía no se limita a la práctica técnica del arduo proceso que entraña organización documental, pues el proceso político es también relevante tomarlo en cuenta para el eficaz desarrollo, funcionamiento y consolidación de los centros bibliotecarios dirigidos a la comunidad en general. Si hasta la fecha en el marco laboral bibliotecario se han estado privilegiando los procesos técnicos, en detrimento de los procesos políticos (MARTINS y FERREIRA, 2018, p. 79), ya es tiempo que tanto en el terreno de la academia como en el plano del trabajo se haga especial énfasis en la relación que existe entre «biblioteconomía y política». Los fundamentos de este nexo estriban en comprender con claridad que en tiempos en que, por ejemplo, la democracia está en riesgo, los profesionales de la biblioteconomía no pueden ni deben permanecer indiferentes y apartados del complejo proceso político y de la acción política. En este sentido se afirma con propiedad inobjetable: "la Biblioteconomía no puede mantenerse exenta y alejada de la participación política" (SPUDEIT y LOBÃO, 2018, p. 157).

El concepto de «biblioteconomía política» es posible razonarlo con base en el escrito Fundamentos sociais e políticos da biblioteconomía de Leilah Santiago Bufrem (1985), académica brasileña de la Universidade Federal do Paraná. El origen de la naturaleza política de las bibliotecas en las diversas coordenadas de tiempo y espacio esta autora lo encuentra en el proceso histórico-cultural de la práctica bibliotecaria, esencia de la biblioteconomía que se ha venido forjando alrededor del mundo. En este sentido, ella asevera: "Los papeles políticos que la Biblioteconomía vienen cumpliendo a través de la historia están íntimamente relacionados con las funciones sociales y educativas que las bibliotecas ejercen" (BUFREM, 1985, p. 120). Funciones que están relacionadas, según hace entrever la autora, con la organización social y política del Estado democrático y republicano. Ciertamente esta visión es apenas una aproximación al concepto en cuestión.

La dimensión política de la biblioteconomía en general y del personal de la biblioteca pública en particular, como elemento que encarna el trabajo bibliotecario dirigido a todos los individuos y grupos de la sociedad, se puede inferir y distinguir teóricamente con algunas ideas expresadas por varios autores. Puntos de vista que de modo habitual han pasado inadvertidos o han sido subvalorados tanto en el plano educativo como en el terreno del ejercicio de la biblioteconomía, tal y como algunos autores sostienen al respecto en ciertos países (SPUDEIT, MORAES y CORRÊA, 2016; JAEGER y SARIN, 2016; MARTINS y FERREIRA, 2018). Esta percepción se puede concretizar cuando se opina, para el caso de Brasil, "que los bibliotecarios no tienen la menor formación política para pensar un poco sobre nuestra sociedad y política" (LAMAS, 2018, p. 47). En concordancia con los planes de estudio que se imparten en las escuelas de varios países iberoamericanos sobre la especialidad, esta limitante que mantiene al personal 
bibliotecario alejado o ajeno a la política probablemente sea el común denominador. Conjetura que es posible comprobar mediante una rigurosa investigación.

Estas premisas, identificadas a través del análisis de la literatura en torno a la temática, las podemos agrupar bajo las categorías de biblioteconomía y bibliotecas.

En torno a la biblioteconomía:

La biblioteconomía puede y debe configurarse como una institución política (SILVA, 2018, p. 217)

Toda la biblioteconomía es política (JAERGER y SARIN, 2016, p. 17)

La biblioteconomía es obviamente política (SHAVIT, 1986, p. 3)

La biblioteconomía se fundamenta en valores políticos ((BUFREM, 1985, p.121)

La biblioteconomía pública está relacionada con la política (SHAVIT, 1986, p. 4)

La biblioteconomía pública es inherentemente política (RUBIN, 2010, p. 175)

En relación con las bibliotecas públicas:

La biblioteca está obligada a funcionar cerca de la política y los políticos (BECKERMAN, 1996, p. 26)

La biblioteca presenta una carga política local (MERKLEN, 2016, p. 80)

La biblioteca es una institución esencialmente política (MERKLEN, 2016, p. 174)

La biblioteca es elemento central del orden político (MERKLEN, 2016, p. 183)

La biblioteca es el espacio político de la democracia (MERKLEN, 2016, p. 284)

La biblioteca es una institución política de la República (MERKLEN, 2016a, p. 150)

La biblioteca es un actor político que apunta a la transformación social (MERKLEN, 2016a, p. 151)

Las bibliotecas y la política son inseparables (VITZANSKY, 2009, p. 117)

Las bibliotecas interactúan constantemente con el mundo político (JAEGER y SARIN, 2016, p. 24)

Las bibliotecas existen en situaciones políticas particulares (DURRANI, 2008, p. 134)

Las bibliotecas son instituciones políticas (BUFREM, 1985, p.121)

Las bibliotecas son parte de la situación política de sus sociedades (DURRANI, 2008, p. 134)

Las bibliotecas siempre han sido un proyecto político (VITZANSKY, 2009, p. 117) Las bibliotecas son herramientas para la acción política (MERKLEN, 2016, p. 80) Las bibliotecas son creación e instrumento de las políticas públicas derivadas del proceso político (BIRDSALL, 2001, p. 3; BIRDSALL, 2005, p. 88)

La biblioteca pública es un mecanismo del sistema político (ÁLVAREZ, 2006, p. 19)

Las bibliotecas públicas son una arena política (SHAVIT, 1986, p. 56)

Las bibliotecas públicas son instituciones políticas y parte del sistema político (SHAVIT, 1986, p. 4).

Las bibliotecas públicas son la guía democrática en los problemas políticos

(DITZION, 1947, p. 74) 
Las bibliotecas públicas conducen naturalmente a iniciativas políticas (BECKERMAN, 1996, p. 17)

En consecuencia podemos aseverar que el bibliotecario público es viable valorarlo como un sujeto político, en tanto que se halla inmerso en la atmósfera tanto de la cultura política como de la política cultural del Estado. El fundamento teórico, para formular y aceptar la idea EI bibliotecario público es un ente político, se encuentra en el significado teórico de cada una de las premisas anteriores; y en el conocimiento del contexto político en el que este trabajador se desenvuelve y en el que actúa en su calidad de ciudadano activo. De esta manera podemos estar de acuerdo, como corolario, con estas otras ideas: Todo gran bibliotecario es un buen político (BERRY, 2014, p. 10) porque: Investidos de un sentimiento del deber, los bibliotecarios asumen una responsabilidad política (MERKLEN, 2016, p. 273).

La idea aristotélica de que "el hombre es por naturaleza un animal político" (Aristóteles, 2000: 4), un zóon politikón, ha sido considerada para afianzar la lógica referente al concepto de «bibliotecario político». Al respecto se dice: "El hombre es, como ser social, también un ser político" (BUFREM, 1985, p. 120). Esto coincide cuando se afirma: "Si el hombre es un ser político", y el bibliotecario es hombre, entonces el bibliotecario también es un ser político" (CÔRTE, 2018, p. 98). Y lo es porque el hombre, como el único animal que pertenece al género humano, vive en el contexto de una sociedad política denominada Estado.

Estas percepciones han permitido rechazar categóricamente la falsa creencia de que las bibliotecas públicas deben mantenerse alejadas de la política y la política, a su vez, distanciada de las bibliotecas públicas (SHAVIT, 1986, p. 1). Por el contrario, es un error pensar y afirmar que el personal de las bibliotecas públicas está o deba estar distanciado o al margen de la política, y que la política está o deba estar separada o aislada de quien hace funcionar este tipo de centros bibliotecarios para el bien público de la sociedad. Es evidente entonces que la categoría del «bibliotecario político» es correlativo y consustancial al concepto de "bibliotecario público», porque la política por naturaleza es un proceso público; porque la biblioteca pública es un importante servicio público que debe garantizar el Estado al pueblo soberano; porque "en el siglo veintiuno las bibliotecas son todavía un proyecto político" (VITZANSKY, 2009, p. 118). Más adelante se abundará sobre este asunto.

La biblioteconomía política, inmanente o consustancial a la práctica política del personal bibliotecario, implica estudiar y analizar los aspectos políticos del servicio de biblioteca, es decir, conocer para actuar en el entorno del proceso político que influye directa o indirectamente en la creación, el desarrollo y el arraigo de esta naturaleza de servicio. Esto sugiere tener presente las diferentes etapas que conforman este proceso: definición, agenda, formulación, adopción, 
implementación y evaluación de políticas (SHAVIT, 1986, p. 7). Desde esta arista, la biblioteconomía pública es un asunto de política nacional porque: "El servicio de biblioteca pública es una función de Estado. El Estado tiene la responsabilidad legal del servicio de biblioteca pública, y la base legal para operar las bibliotecas públicas se funda en las leyes de cada Estado" (SHAVIT, 1986, p. 89). En este sentido, la importancia del papel del Estado en torno a la biblioteconomía pública nos ayuda a configurar el perfil político de la biblioteconomía como noción práctica de la bibliotecología.

La biblioteconomía relacionada con la política tiene el compromiso de consolidar el quehacer bibliotecario con espíritu político, por ende, de forjar un perfil de la biblioteca pública tanto social como político. Entre los rasgos peculiares de esta figura socio-política destaca la garantía, el respeto y la defensa de los diversos valores de la democracia, para así atenuar las desigualdades que existen entre ricos y pobres en información y conocimiento. El peligro que corre la democracia ante el desarrollo del fascismo societal, como nueva forma de fascismo que explica el sociólogo lusitano Boaventura de Sousa Santos (2005: 38-44), no debe pasar inadvertido para los trabajadores y los estudiosos de la biblioteconomía pública, pues este fascismo persigue la privatización de los servicios públicos en general, apuntalada en el proceso del marketing bibliotecario que atenta contra el funcionamiento público de las bibliotecas (MENESES, 2017a). Asunto que pone en riesgo "la propia sobrevivencia de la democracia" (MATOSO, 2018, p. 11) y, consecuentemente, corre peligro la perduración de la biblioteca pública en el siglo que transcurre. Asimismo, como se percibe en el contexto brasileño:

\footnotetext{
En vista que actualmente la sociedad pasa por un complejo momento de transformaciones, juego de fuerzas, en los más diversos campos, la Biblioteconomía no puede mantenerse exenta y alejada de la participación política, comprendemos ser ese momento de intensificación, reconquista de la democracia, lucha y constante diálogo con la comunidad en la que los bibliotecarios se insertan (LOBÃO, 2018, p. 185).
}

La biblioteconomía política, como disciplina práctica de la bibliotecología política, es viable construirla con el pensamiento y la acción; es admisible formularla mediante el estudio y análisis de la literatura especializada que versa sobre esta gran temática y a través de una rotunda y decisiva participación del personal bibliotecario en el mundo de la política. Por ende, no se puede soslayar el siguiente rubro.

\section{Actividad técnica y actividad política de los bibliotecarios públicos}

En la esfera del quehacer correspondiente a la comunidad de bibliotecarios públicos observamos, por un lado, la actividad técnica referente a la aplicación de habilidades, metodológicas, técnicas y administrativas ceñidas al conocimiento adquirido en los campos de 
la bibliografía, biblioteconomía, bibliotecología y disciplinas afines; por otra parte, se distingue la actividad política alusiva a los actos que evidencian política pública bibliotecaria en la marco del proceso político del Estado. Esta división de actividades, en el plano de las bibliotecas públicas, nos puede servir no solamente para separar con claridad la función técnica de la función política que desempeña este tipo de personal bibliotecario, sino también para saber apreciar la relación que puede existir entre ambas funciones. En el mundo del servicio de la biblioteca pública, la práctica bibliotecaria, con visión profesional, se ha ido sistematizando al amparo de quienes estudian bibliotecología y/o biblioteconomía; y este servicio se ha extendido gracias a quienes apoyan esta práctica con su trabajo auxiliar. Así, es posible distinguir y valorar tanto el trabajo que realizan los bibliotecarios profesionales como los bibliotecarios auxiliares.

Si bien la actividad política, en el mundo moderno de las bibliotecas públicas, se ha estado llevando a cabo desde que comenzaron estas instituciones su andadura a mediados del siglo XIX, este marco ha resultado difícil de entender y explicar debido a que, recalquemos, las escuelas de biblioteconomía, bibliotecología y ciencias de la información han pasado prácticamente inadvertida la perspectiva política de las instituciones bibliotecarias en sus respectivos planes de estudio. A pesar de que vivimos en determinados contextos políticos durante toda la vida, y de que ya existe una relevante literatura especializada que versa en torno a la estrecha relación entre bibliotecas y política, en eventos académicos y de trabajo se siguen privilegiando los temas de carácter técnico-administrativo sin ninguna mira que involucre reflexiones de naturaleza explícitamente política. De tal suerte que no es novedad que los bibliotecarios públicos generalmente continúen practicando el dogma ortodoxo que por tradición ha estado separando la política de la administración (SHAVIT, 1986, p. 3), desestimando el proceso político de la administración bibliotecaria.

Sabemos que la relación que existe entre «ciudadanía e información» está estrechamente relacionada con el nexo «bibliotecas y democracia», por ende, con la conexión «bibliotecas públicas y participación ciudadana». En concordancia con la correspondencia de estas categorías, debemos comprender en su justa dimensión la necesidad de contar con "bibliotecarios más politizados para que actúen en forma protagonista y no sólo como reproductores del orden social y político vigente" (SILVA, 2018: 219). Actuar políticamente en este sentido significa pensar en la participación bibliotecaria sobre asuntos que afectan a la comunidad de lectores y usuarios, así como al funcionamiento social del servicio de biblioteca pública en el marco del Estado democrático de derecho. Entorno que requiere más actividad política que actividad técnica; ámbito que demanda no solamente de avezados bibliotecarios técnicos, sino también de experimentados bibliotecarios como agentes de transformación social; como sujetos políticos diestros en poner en marcha proyectos con clara visión de 
emancipación humana, y en defensa de los derechos sociales, políticos, civiles y culturales. En efecto: "Si las bibliotecas combaten la ignorancia, deben asegurarse de que los ciudadanos las utilicen y las vean como depósitos de ideas democráticas y como elementos centrales para el funcionamiento de la democracia" (GORMAN, 2000, p. 163). En esta contextura, la función democrática que desempeñan las bibliotecas públicas es la esencia fundamental de la práctica política del personal bibliotecario que labora en estos espacios de lectura, información y recreación destinados para el pueblo.

$\mathrm{Si}$ es que mediante la actividad técnica el personal bibliotecario que atiende a la población en general, a través de las colecciones que desarrolla, organiza y circula, y los servicios que gestiona, puede y debe pensar en encontrar las formas de relacionar sus labores técnicas con la actividad política. Este punto de vista concuerda con el undécimo principio de la biblioteconomía que planteó hace más de cuatro décadas Thompson en obra $A$ history of the principles of librarianship, el cual reza: "El papel de un bibliotecario solo puede ser importante si está completamente integrado dentro del sistema social y político prevaleciente" (1977, p. 218). Esto sugiere que el gremio de bibliotecarios públicos se mantenga informado en torno a la gama de políticas públicas que gestiona el gobierno, como relevante componente del proceso político que engloba el servicio público de biblioteca. Por esto cobra especial relevancia razonar sobre el siguiente asunto.

\section{La naturaleza política de la biblioteca pública}

Los elementos, valores y principios vinculados al carácter político de la biblioteca de todos y para todos están relacionados con su institucionalidad pública, entendida como un atributo primordial en concordancia con 1] la democracia como régimen político basado en la voluntad del pueblo para elegir con libertad a sus representantes populares y 2] la república como sistema político, fundado en el imperio de la ley y en la igualdad de los ciudadanos ante la ley. Esta institucionalidad gira en torno a dos criterios: 1] el relativo a garantizar al pueblo el derecho democrático de libre acceso a la información documental organizada y 2] el concerniente a satisfacerla gama de necesidades sociales de información que presentan las diversas comunidades de lectores y usuarios para formarse como ciudadanos activos en la esfera de la "cosa pública". Contextura que implica formar para la ciudadanía con perspectiva éticopolítica, complemento a una acción educativa que apunte a procurar el bien común y a favorecer el cambio social que permita lograr una vida buena para todos (YURÉN, 2013, p.26), incluido un buen gobierno. El siguiente acontecimiento es elocuente en este sentido:

Durante las primeras décadas del siglo $X X$, se crearon bibliotecas municipales de referencia como parte de un movimiento para reformar el gobierno de la ciudad en los 
Estados Unidos. Su misión: recopilar y difundir información para mejorar la toma de decisiones sobre políticas, aumentar la eficiencia de la administración pública y crear un electorado con educación política (SEAVER, 2004, p. 7).

Se trata entonces de una institucionalidad encaminada tanto a ofrecer recursos y servicios para cubrir carencias de conocimiento entre la ciudadanía como para asegurar el derecho humano de acceso a la información de los diferentes individuos y grupos sociales. Se trata de una institucionalidad al servicio de las personas y en pós del bien que beneficie a mujeres y hombres, sin distinción alguna. Así, tengamos en cuenta: "Por los hechos de su existencia, la biblioteca pública es una institución pública, y en común con todas las demás formas de esfuerzo público, la biblioteca está obligada a entrar en contacto con la política y los políticos" (BERKERMAN, 1996, p. 26). En esta perspectiva, la institucionalidad pública del tipo de biblioteca que nos ocupa se instituye en una institucionalidad política y social, cuyo objetivo final es proporcionar el mejor servicio posible al pueblo conformado en sociedad. Abundemos al respecto.

Para percibir la esencia política de la biblioteca pública es necesario pensar en diversos puntos que fomenten la reflexión crítica. Uno de ellos es el reconocer que esta institución es por antonomasia un servicio público, noción que se estudia en diferentes marcos epistemológicos tales como: la ciencia política, la teoría general del Estado, la administración pública y el derecho administrativo, público y municipal. Al reconocer a este centro bibliotecario como servicio público, estamos concordando que, en efecto, la biblioteca pública es una institución política porque se observa en el marco de los servicios que por ley debe crear, desarrollar y consolidar el Estado para el bienestar del pueblo. El administrador político institucional, encargado del eficaz funcionamiento de un sistema de bibliotecas públicas, es el gobierno organizado mediante el aparato de la Administración Pública. En este sentido, el cuerpo gubernativo es el brazo ejecutivo del Estado. Desde esta perspectiva, es innegable la naturaleza política del servicio público denominado biblioteca pública. Conforme a esta explicación, cabe recalcar los postulados: las bibliotecas públicas son instituciones políticas, las bibliotecas son parte del sistema político, en consecuencia, los bibliotecarios públicos son sujetos políticos.

La biblioteca pública es una institución política no porque tenga la potestad de crear estructuras y mecanismos para regular el orden social, sino porque tiene la posibilidad de colaborar en la construcción de una ciudadana informada, ilustrada y participativa, elemento humano esencial de la democracia como forma de vida (MENESES, 2008); porque desempeña el papel de guardiana de la libertad de acceso a la información, derecho humano fundamental en la vida política de toda nación civilizada; porque garantiza, transmite y afianza valores como la libertad, la igualdad, la justicia, la equidad y el respeto a través de los recursos, servicios y 
espacios que brinda a la comunidad. En tal sentido, este tipo de biblioteca influye o debería de influir en la vida política de la nación para lograr un orden social democráticamente estable. Así, con base en el punto de vista del sociólogo Denis Merklen (2016a, p. 151), la biblioteca pública, como institución democrática y republicana, es un actor político esencial que puede favorecer el cambio social. En este marco de ideas, la naturaleza política de la biblioteca pública concuerda con las premisas que la postulan como "un espacio político de la democracia" (MERKLEN, 2016, p. 284) y como “una institución política de la República” (MERKLEN, 2016a, p. 150).

Así, las bibliotecas públicas y las escuelas públicas se yuxtaponen porque las personas en su posición de ciudadanos deben aprender a leer críticamente para juzgar las leyes, conocer sus derechos y obligaciones e ilustrarse para ejercer la libertad, la justicia, la equidad, el respeto, la solidaridad, entre otros valores afines; así como para adquirir los conocimientos necesarios que permitan comprender la filosofía política del servicio del bien público. De la lectura crítica, forjada y cultivada en escuelas y bibliotecas, se deriva la capacidad crítica de la ciudadanía tanto para el desarrollo de la vida pública como para su eficaz participación en asuntos públicos. Por esto la biblioteca abierta para todos los grupos sociales debe ser una política de Estado para que figure como la principal institución político-educativa destinada a favorecer a todas aquellas personas que ya no están inscritas en la educación formal. Consecuentemente, la biblioteca pública debe ser valorada como una institución necesaria en el texto de la Constitución Política del Estado y en el contexto en el que se aplica esta norma jurídica suprema que rige la organización política del Estado.

La institucionalidad política de la biblioteca pública se distingue porque es un servicio público instituido en, por y para la democracia y la república, en el marco de un Estado de derecho; porque es parte de los servicios públicos que gestiona el Estado y administra el gobierno a través del complejo aparato ejecutivo de la Administración Pública. Desde esta perspectiva, se reconoce que este servicio de biblioteca: 1] se sostiene con presupuesto público, 2] este presupuesto procede de la hacienda pública o de la recaudación fiscal que mantiene la ciudadanía, 3] forma parte de la estructura pública gubernamental y 4] constituye parte del proceso político al ser afectado por este en su gestión y financiación (GARCÍA y SUTHERLAND, 2001 , p. 13).Esta percepción coincide en cierta manera en relación con la apreciación político gubernamental de la biblioteca pública (MENESES, 2013, p. 4), pues esta institución de servicio, destinada para toda la población, es:

1] Objeto de políticas de equipamiento (construcción, remodelación o ampliación de los edificios de bibliotecas públicas al servicio de la comunidad); 2] Materia de políticas de educación pública (Visto este tipo de biblioteca como auxiliar del sistema de las escuelas públicas enclavadas en el nivel básico); 
3] Cuestión de políticas de información (el servicio de biblioteca pública como institución garante para construir una ciudadanía informada);

4] Asunto de políticas de recreación cultural (la biblioteca pública activa que permita el disfrute libre, gratuito y sin discriminación alguna, de las distintas manifestaciones culturales para el pleno desarrollo de los presentes y futuros ciudadanos); $y$

5] Tema de políticas de bienestar social (prestación del servicio público de biblioteca con el fin de que los miembros de la comunidad logren una mejor calidad de vida).

En concordancia con esta estimación y en torno a la biblioteconomía pública, concebida como la práctica primordial de la bibliotecología en materia de bibliotecas públicas, se afianza, desde la visión gubernativa, la idea: toda la biblioteconomía es política, y las bibliotecas siempre han sido un proyecto político, adquiriendo así una particular relevancia para entender y recalcar que, en efecto, la biblioteca pública es una institución política de la República (MERKLEN, 2016a, p. 150), y es el espacio político de la democracia (MERKLEN, 2016, p. 284). Es, por ende, una institución social adherida al proceso político que caracteriza al Estado democrático y republicano de derecho. En relación con el paradigma democrático de la biblioteca pública, en la esfera de la biblioteconomía internacional, giran varias ideas fundamentales. Considerada como institución democrática, se infiere que: 1] educa para la vida democrática, 2] actúa a favor de la libertad de acceso a la información, 3] ejemplifica los valores democráticos al estar "abierta a todos" y 4] brinda pluralidad de ideas y puntos de vista (BYRNE, 2007, p. 28) mediante la bibliodiversidad de sus colecciones, o sea a través de la diversidad cultural concerniente al universo del libro.

Esta naturaleza política de las bibliotecas públicas contrasta con la errónea percepción que sostiene que estas instituciones deben mantenerse neutrales en relación con la compleja esfera de la política. Esto es:

\begin{abstract}
Las bibliotecas públicas también han intentado abrazar durante mucho tiempo la postura de permanecer como árbitros imparciales de la información, que se ha caracterizado inútilmente como una posición de neutralidad. Aunque se pretende que sea una manera de mantenerse imparcial ante el público, el resultado final es contraproducente, ya que esta postura se ha interpretado con demasiada frecuencia en el sentido de que las bibliotecas públicas deben permanecer como espectadores en los debates políticos que afectan su capacidad para funcionar (JAEGER, GORHAM, BERTOT Y SARIN, 2014, p. 4).
\end{abstract}

De tal modo que la profesión bibliotecaria ha estado siendo socavada por el mito que ha venido inculcando que las bibliotecas públicas no son instituciones políticas, que la biblioteconomía pública es apolítica (SHAVIT, 1986, p. 1-5). Motivo por el cual muchos de quienes ejercen este trabajo simplemente no han querido involucrarse en asuntos más allá de 
lo que atañe a la práctica técnica de hacer funcionar una biblioteca. Es por esto que en el campo de la profesión se ha dificultado entender que las bibliotecas públicas comúnmente son muy afectadas por la toma de decisiones que se lleva a cabo en los diversos ámbitos de la política y de lo político, mismos que dan forma a la financiación, las actividades y los roles de las bibliotecas en la sociedad (JAEGER, GORHAM, BERTOT y SARIN, 2014, p. 4). Si pensamos que el servicio público de biblioteca es parte esencial de la naturaleza política del sistema de gobierno, entonces cabe no perder de vista lo que Shavit escribió hace tiempo: "Una estructura gubernamental como la biblioteca pública nunca puede ser neutral. No importa cómo se diseñe, la biblioteca pública suele beneficiar a algunos grupos más que a otros" (1986, p. 3). Esto independientemente de los principios de igualdad y equidad que orientan en la práctica democrática a estos centros bibliotecarios.

Así las cosas, es imposible que la fuente de trabajo del bibliotecario público sea neutral, pues "una biblioteca verdaderamente pública... es un instrumento de liberación" (FLUSSER, 1980, p. 137) para las clases subalternas. Consecuentemente, el comportamiento político de las bibliotecas públicas en el escenario de las luchas de clases es una realidad inobjetable, tal como se aprecia en el contexto de la biblioteconomía brasileña (SILVA y SILVA, 2010). El valor de la neutralidad en torno a la biblioteca pública y a su personal bibliotecario se quiebra, asimismo, en tiempos de guerra (MENESES, 2013), o durante severas crisis sociales y políticas. En efecto, la posición de neutralidad es difícil sostenerla cuando la biblioteca se convierte en un agente político en situación de conflictos políticos agudos (MERKLEN, 2016, p. 308). En este escenario de ideas resulta pertinente lo que expresó el bibliotecario británico-keniano, Shiraz Durrani, en uno de sus escritos con evidente dimensión política:

El mito de un servicio de bibliotecas públicas "neutrales" necesita ser refutado. No hay manera de que las bibliotecas y los bibliotecarios sean o puedan ser neutrales en las luchas sociales de sus sociedades. Cada decisión que toman cuánto gastar en libros, qué libros comprar, qué personal designar, cómo administrar el servicio- es un reflejo de su posición de clase y su perspectiva mundial, por mucho que lo nieguen.

En todas las sociedades con divisiones de clase y lucha de clases, los servicios bibliotecarios tienden a ser un servicio para la elite por la elite, proporcionando un servicio a las clases dominantes y sus aliados solamente. En situaciones como estas, el proceso de liberación del servicio de biblioteca para los excluidos previamente es el papel clave de los trabajadores y profesionales de la biblioteca. (DURRANI, 2008, p. 124-125)

El debate sobre la naturaleza política de la biblioteca pública echa por tierra la tenaz idea que afirma: "el bibliotecario no debe ser en su práctica profesional, ni izquierda, ni de derecha, o de centro, debiendo ser totalmente apolítico y neutro". Adherirse a esta percepción, a todas luces política, es una manera de utilizar a los bibliotecarios públicos y a las instituciones 
bibliotecarias dirigidas a la sociedad en general, "como armas de control" (SILVA, 2018, p. 214).La filosofía política de Durrani, en torno al servicio de biblioteca pública, apunta en sentido contrario al inferir que esta se debe crear con el fin de beneficiar esencialmente al pueblo para que este elemento que encarna al Estado tenga la oportunidad de generar actos de liberación, momentos de emancipación. Para tal efecto, "existe una necesidad urgente de crear un nuevo tipo de bibliotecas y bibliotecarios democráticos, orientados al pueblo, que respondan directamente a las comunidades a las que sirven" (DURRANI, 2008, p. 124). La aspiración política a la liberación debiera ser acogida en la comunidad bibliotecaria como un signo de los tiempos de crisis que vivimos. Para Durrani el reto que enfrentan los bibliotecarios es el de saber utilizar políticamente la información para comenzar a liberar a los explotados y oprimidos por el dominio de la globalización capitalista. Servicios bibliotecarios que ayuden a orientar el espíritu crítico de la comunidad y a estimular la voluntad individual y colectiva de emancipación.

La perspectiva política de la biblioteca pública se vincula a la singularidad política de la información en general y al atributo de la información política en particular. Primero, si los recursos documentales de esta naturaleza de centro bibliotecario es en esencia para construir una mejor ciudadanía desde diferentes aristas (MENESES, 2008), la tónica general de los contenidos de las colecciones bibliográficas, que previamente desarrolla y organiza técnicamente su personal, adquiere un elevado valor político en los cuadrantes de la democracia y la república. Segundo, si la información documental es un bien social para que la comunidad pueda adquirir la capacidad política necesaria que apunte a ejercer y cumplir derechos y obligaciones políticas, la información política es un "bien socialmente necesario" para que la ciudadanía pueda satisfacer sus necesidades "de conocimientos y de expresión en materia política" (SOSA, 2001, p.291). Esto con miras a poder participar libre y activamente en la esfera pública, la cual se rige por el uso público de la razón. De tal modo que la relación bibliotecapolítica se complementa con el nexo información-política. Contextura teórica que nos puede permitir denotar y apuntalar proyectos, programas, planes y actividades de formación cívicopolítica, esto es, de formación o educación ciudadana (MAGENDZO, 2004; CONDE, 2006). Esta gama de aprehensiones nos conduce al siguiente discurso.

\section{La praxis política del bibliotecario público}

Uno de los desafíos del personal de la biblioteca pública es la carencia que tiene en materia de formación sobre educación política con perspectiva bibliotecológica; y de educación bibliotecológica con visión política. Esta limitante es lo que no nos ha permitido que este personal piense y actúe políticamente tanto en determinadas circunstancias como durante una gran diversidad de coyunturas sociales, políticas, culturales e ideológicas. Momentos que a 
veces afectan directa o indirectamente la creación, el desarrollo y la estabilidad de este servicio de biblioteca. En efecto, como se afirma: "Es siempre complejo hablar de política, hay muchas teorías y conceptos que implican este término, y es aún más difícil abordar la actuación política del bibliotecario, ya que no recibimos en términos académicos, ninguna formación para actuar políticamente" (TAVARES, 2018, p. 141). Significa entonces que la praxis política del personal de las bibliotecas públicas infiere la necesidad de saber para razonar y participar políticamente, con el fin de propiciar cambios positivos que beneficien a la comunidad y al individuo, a la diversidad cultural de grupos. Esto implica "introducir la mayor racionalidad en la práctica" (SÁNCHEZ, 1997, p. 28). Es decir, la praxis política está vertebrada por el proceso teórico de la interpretación y el proceso práctico de la transformación del mundo. De modo que pensar el mundo para cambiarlo no solamente es cuestión teórica, sino también práctica, pues la "praxis creadora" fusiona ambos aspectos (SÁNCHEZ, 1997, p. 23). En este estado, en el que confluye reflexión y acción, se requiere contraer un acendrado espíritu de compromiso con la sociedad. Así, es tiempo de que la praxis bibliotecaria (TARGINO, 1997), adherente a la praxis biblioteconómica (BUFREM, 1985, p. 110), se configure explícitamente en praxis política inherente al quehacer bibliotecario, en torno de la que se compagine el elemento teórico con el elemento práctico. Una manera de entender, aunque de modo fragmentario, las relaciones que coexisten entre teoría y práctica, pensamiento y acción, interpretación y transformación, lectura pública y cambio social en el escenario de la praxis política del bibliotecario público, es el punto de vista que afirma:

\footnotetext{
Quizás ha llegado el momento de que más bibliotecas se muevan para pasar de la pasividad a la intervención en la política, no en el sentido de tomar partido político, sino en proporcionar la información y el conocimiento registrado que los ciudadanos necesitan y alentar una discusión informada y conocedora de la política pública. (GORMAN, 2000, p. 163)
}

Si las bibliotecas públicas presentan una gran carga política y si las observamos como herramientas para producir acción política, como infiere Merklen (2016, p. 80), entonces también es posible contemplarlas como mecanismos para generar pensamiento político. En consecuencia, la praxis política del bibliotecario público nutre la praxis político-ciudadana de la comunidad de lectores y usuarios que atiende. Es decir, las bibliotecas públicas politizan su esencia mediante sus colecciones, recursos y servicios porque 1] brindan orientación política a pensamientos y movimientos que la requieren, y 2] ofrecen contenido político a personas y grupos que no lo tenían.

Debido a esto, el personal bibliotecario del siglo XXI tiene la responsabilidad de reconocer, cultivar y asumir una clara praxis política. Por ende es necesario que se acerque al conocimiento de la teoría política, por un lado, y conozca el complejo funcionamiento de la 
política práctica, por el otro. El conocimiento teórico de la política infiere saber conceptos, esquemas y tendencias que se encuentran en el campo de la ciencia política y disciplinas afines; conocer el funcionamiento democrático y republicano de la política práctica implica observar la estructura y el funcionamiento gubernamental del Estado, constituido comúnmente por los tres poderes públicos tradicionales: el poder ejecutivo, legislativo y judicial. En virtud de su complejidad, especial atención demanda el análisis relativo al aparato denominado Administración Pública, regulado por el poder ejecutivo.

La comunidad de bibliotecarios públicos tiene claro el panorama relativo a que las bibliotecas públicas son instituciones, con atributos tanto democráticos como republicanos, que gestionan y disponen de servicios al público, servicios dirigidos a la comunidad y al individuo. Pero no basta con esta perspectiva, si deseamos entender la esencia política de la biblioteca pública es menester también tener presente que este centro bibliotecario es un bien público, noción que adquiere un significado jurídico-político porque se trata de un asunto que compete al Estado. En virtud del papel vital que desempeñan estos espacios de lectura destinados para todo el pueblo, se asevera: 1] "La noción de bien público es esencial para la noción de biblioteca pública" (D’ANGELO, 2006, p. 11); y 2] "La biblioteca pública ahora es la quintaesencia del bien público" (JAEGER, GORHAM, BERTOT y SARIN, 2014, p. 23). Si el tipo de biblioteca que nos ocupa es una institución social de servicio público, entonces es también una institución política de bien público disponible para realizar el bien común. La idea correlativa bien público-bien común, vista a través de la gestión de los servicios públicos a cargo del Estado, entre ellos el servicio de biblioteca pública, infiere conocimiento de la teoría política o de la ciencia política (GONZÁLEZ, 1995, p. 461). El perfil político del bien público, en el entorno de la biblioteca pública, es parte inherente de la praxis política del bibliotecario público porque el bien público "es un elemento indispensable para el desarrollo y perfeccionamiento de la persona humana" (PORRÚA, 1998, p. 419) y de la comunidad.

Consecuentemente, quienes laboran en el sector de los sistemas y redes de bibliotecas públicas deben preocuparse y ocuparse por mejorar "la percepción de que la biblioteca pública es un bien común de primer orden" (GARCíA y SUTHERLAND, 2001, p. 14). Es decir, un servicio público fundamental del que se puede y debe beneficiar el pueblo, elemento esencial del Estado. Así, el servicio de este tipo de bibliotecas tiene como objetivo político lograr el bien común público a través de sus acervos, recursos y servicios que pone a disposición libremente de los diversos grupos etarios que constituyen la sociedad. Esta percepción va más allá de la típica y escueta idea a la que a menudo recurre el gremio bibliotecario y que dice: las bibliotecas, en general, tienen como finalidad principal la satisfacción de las necesidades de información del usuario. Planteamiento tradicional que recalca hasta el cansancio la administración bibliotecaria 
ajena, en lo general y en lo concreto, a una genuina praxis político-bibliotecaria. Por ende, es tiempo ya de no continuar con una gestión de servicios bibliotecarios indiferente u omisa a todo espíritu democrático. En este sentido, es pertinente poner en práctica el principio de inclusión social, esto es:

El desafío es desarrollar un servicio que esté abierto a todos, independientemente de la clase, raza, género, capacidad, edad, orientación sexual, creencias políticas, etc. El servicio debe ser incluyente, que llegue a todos los que actualmente están excluidos. Sin embargo, esta tarea no es fácil y requiere una cuidadosa reflexión y planificación. (DURRANI, 2008, p. 125)

Pensar y actuar políticamente, en la esfera del servicio de biblioteca pública, exige implicarse en la contextura de la cultura política, pues como se afirma: "En todos los países realmente democráticos, los ciudadanos gobiernan a través de los representantes políticos a quienes han votado; estos representantes nombran a su vez a otros cargos públicos en su Gobierno, del que las bibliotecas públicas son una parte ineludible (GARCÍA y SUTHERLAND, 2001 , p. 14). Esta cultura incluye el conocimiento y la observación de preponderantes sujetos políticos, tales como: los partidos políticos, los sindicatos, las asociaciones y los grupos que practican la política de manera permanente, y de donde emanan los individuos políticos en su calidad de ciudadanos, militantes, electores, electos y funcionarios públicos (CERRONI, 1997, p. 97). Contexto en la que la biblioteca pública puede y debe ser incluida como proyecto de cultura política en momentos de construcción de ciudadanía (MENESES, 2008, p. 117-120; MEDEIROS, 2010, p. 14-17), de alfabetización política, de jornadas electorales, de movilización ciudadana en defensa de sus derechos y otros. Con base en todo lo anterior, nos falta esclarecer la noción central que a continuación se puntualiza.

\section{El concepto de bibliotecario político}

Ya en otro documento se planteó que una definición verdaderamente expresiva del término bibliotecario público brilla por su ausencia en la literatura especializada, a pesar de que esta noción se encuentra frecuentemente en artículos y libros que versan sobre el tema de bibliotecas públicas (MENESES, 2014a). Ante esta laguna no nos asombre que no se haya tampoco aún percibido ni analizado el concepto de bibliotecario político a la luz, por ejemplo, de los diversos postulados antes mencionados.

La aseveración: "Ser bibliotecario en una biblioteca verdaderamente pública es desarrollar de una manera política su profesión" (FLUSSER, 1980, p. 137), nos permite inferir que el «bibliotecario político» es una expresión correlativa de la palabra clave «bibliotecario público». Entonces es viable y pertinente tener en cuenta la dimensión política del personal de las bibliotecas públicas, la cual está configurada por el funcionamiento de estas instituciones en 
los marcos sociales, culturales, ideológicos y políticos del Estado. Esto comienza a cobrar sentido cuando recurrimos a la definición genérica, pero con perspectiva política, del sujeto que nos ocupa:

El bibliotecario público es aquel que administra responsablemente colecciones, servicios y recursos estatales de una biblioteca en razón de su formación, habilidades y experiencia para servir a la sociedad y al Estado; es un ciudadano que brinda el servicio público de biblioteca, a gobernantes y gobernados, con un espíritu de utilidad social y labora apegado a valores, derechos y obligaciones; es un servidor público que mediante su oficio asiste al Estado (MENESES, 2014a, p. 204).

Con base en esta conceptualización, el bibliotecario público es quien hace funcionar todas las bibliotecas que pertenecen al sector público. Es decir, esta perspectiva definitoria va más allá de lo que comúnmente se afirma que es un bibliotecario al servicio de una biblioteca de prototipo general y que como tal está dirigida a servir a todos los miembros de la sociedad. Entonces nos falta circunscribir una definición operativa que nos permita vincular el término de bibliotecario público con el de bibliotecario político en el universo de lo que tradicional o convencionalmente reconocemos como bibliotecas públicas. Se sugiere la siguiente definición: El bibliotecario político es el ciudadano responsable que desarrolla, organiza y consolida colecciones, servicios y recursos del Estado para administrar técnica, social y políticamente una biblioteca pública, con base en su formación, capacitación, destrezas y experiencia para así brindar servicios de información, educación y recreación a la comunidad, basados en principios y valores democráticos y republicanos. Más aún, el bibliotecario político es quien está atento a las políticas públicas que le conciernen y de lo que acontece en la contextura del proceso dinámico de la política para pensar y actuar en consecuencia. Desde esta arista, el perfil del bibliotecario político exige conocimiento en relación con la comunidad a la que sirve, es decir:

\footnotetext{
Para que el bibliotecario pueda actuar políticamente, necesita conocer el contexto social en el que está involucrado. Es necesario que él conozca bien su entorno, las demandas sociales de su comunidad, el momento político en que vive. Sólo a partir de esa implicación es posible actuar de forma social y políticamente relevante, compartiendo contenidos de valor puede realmente transformar la calidad de vida de su público objetivo.
}

Su actuación en unidades de información deberá ser firme contra la censura y el prejuicio de cualquier naturaleza y, al mismo tiempo, firme a favor de la democracia, del respeto a las diferencias y de la búsqueda del bien común. Deberá ser inclusiva, atenta en cuanto a posibilitar el acceso a discapacitados físicos y cognitivos y luchar contra cualquier tipo de discriminación (CORRÊA y PRADO, 2018, p. 117).

El bibliotecario político, en el contexto de las bibliotecas abiertas para todos los grupos sociales, no está apegado solamente al trabajo técnico ya que muestra afán e interés especial por la vida política, por el bien público, por las políticas estatales que atañen a su labor y por el proceso político que influye de algún modo en su campo de trabajo. En este sentido, se entiende 
que la actuación política del bibliotecario público está vinculada directamente a dos factores. El primero es con respecto a su formación como ciudadano; el segundo tiene que ver con la mirada crítica y comprometida de las políticas públicas que interfieren a diario en su ejercicio profesional (CÔRTE, 2018, p. 93). La formación ciudadana del personal de la biblioteca pública es esencial tomarla en cuenta para su desempeño político informado, para su participación política en beneficio de la comunidad y del que hacer bibliotecario en sí. Dicha formación es un proceso permanente y durante todas las etapas de la vida, el cual se nutre mediante el análisis político que debe hacer del entorno de la sociedad política en la que se desenvuelve. Así: "Pensar la actuación política del bibliotecario es pensar que todo ser es político, social, independientemente de su profesión. Sin embargo, el bibliotecario, debido a su ambiente de trabajo y del carácter humanista de la profesión, necesita, sin lugar a dudas, velar por el ejercicio político de la profesión" (CÔRTE, 2018, p. 104). Esto infiere que la biblioteconomía es una profesión, en efecto, adherente a la política. Pero el entorno laboral del personal bibliotecario no se reduce a la perspectiva humanista porque la naturaleza de su acción gremial comprende también alcances sociales y, por supuesto, políticos.

La actuación política del bibliotecario público requiere conocer bien tanto el contexto social en el que está involucrado como el entorno en relación con las demandas sociales de su comunidad; esto infiere percatarse del contexto político en que vive. Así, actuar políticamente de forma relevante implica esforzarse para lograr el objetivo de transformar la calidad de vida de los grupos sociales que atiende. De tal modo que el concepto de bibliotecario político entraña actuar con firmeza contra la censura y los prejuicios de toda índole que pudiesen obstaculizar el cumplimento de los valores de la democracia, el respeto a las diferencias y el alcance del bien común. En este sentido el comportamiento político de este profesional de la información debe ser incluyente, comprometiéndose en el servicio público que brinda a la comunidad, para así garantizar el acceso a personas con discapacidad físicas y luchar contra cualquier tipo de discriminación (CORRÊA y PRADO, 2018, p. 117).

En este orden de ideas, la democracia en sus diferentes dimensiones, es decir, como forma de Estado, de gobierno y de vida, no debe pasar inadvertida para quien se asuma como bibliotecario político, pues: "La promesa de un ideal democrático es punto de convergencia de todas las nuevas posibilidades en el terreno de la Biblioteconomía y de ello deriva otra actitud de trabajo" (BUFREM, 1985, p. 113). Si la biblioteca pública se concibe como espacio público, entonces este tipo de centro bibliotecario es, sin duda, un importante espacio político de la democracia (MERKLEN, 2016, p. 284) y de la república (MERKLEN, 2016a, p. 150). En efecto, una de las relaciones fundamentales en el universo político de las bibliotecas públicas es precisamente la referente a «bibliotecas y democracia» (MENESES, 2008), nexo que se cultivó 
con particular énfasis durante el siglo XX. Los puntos de vista de Jaeger, Gorham, Bertot y Sarin avalan la esfera democrática de estas instituciones al escribir:

Profesionales y académicos de bibliotecas públicas han articulado durante mucho tiempo el valor de las bibliotecas públicas como elementos centrales de la democracia, dando lugar a frases tan repetidas para describir a las bibliotecas públicas como arsenales de la democracia. [...]. Las bibliotecas públicas son, de hecho, instituciones fundamentalmente públicas que sirven para informar al público y aliviar problemas sociales, que claramente pueden apoyar a una sociedad democrática saludable (2014, p. 42).

A la luz de un republicanismo moderno (RABOTNIKOF, 2006), cabe pensar en los espacios adecuados para ejercer la libertad pública, la educación y la lectura públicas. La biblioteca pública, dadas sus funciones sociales, política y cultural que desempeña, pasa a formar parte importante de las instituciones republicanas en la modernidad. Es el ideario republicano que lleva directamente al desarrollo de las instituciones de educación pública (McCABE, 2001, p. 9), entre ellas las bibliotecas públicas en tanto que desarrollan una importante función de educación. En el contexto de este servicio público, la libertad se observa como una relevante libertad política que entraña la libertad de acceso a la información y la libertad de leer con perspectiva de diversidad cultural y espíritu político. La libertad política en la esfera de la práctica bibliotecaria implica hacer realidad el modelo democrático que conlleva igualdad, justicia y equidad. Valores presentes en varias declaraciones y manifiestos internacionales referentes al funcionamiento de la institución bibliotecaria que nos ocupa. En este sentido "es importante señalar que los bibliotecarios han reconciliado los ideales democráticos con la práctica política mediante una práctica general” (GARCEAU, 1949, p.133). De tal manera que la tradición republicana de la escuela pública se refuerza con el apoyo institucional de la biblioteca con visión democrática. Si es que la base filosófica de la biblioteca pública moderna, con perspectiva republicana, se relaciona con la biblioteconomía cívica (McCABE, 2001). En este orden de ideas, el bibliotecario público cobra un gran potencial político en el marco de la educación ciudadana, pues entre los objetivos esenciales de la biblioteca pública destaca el "promover la ciudadanía ilustrada" (GARCEAU, 1949, p. 143). Es decir: "La biblioteca, entre otros propósitos, fue creada como una fuente de conocimiento para una ciudadanía informada, en cuyo juicio colectivo descansa el éxito o el fracaso de la democracia responsable" (GARCEAU, 1949, p. 51).

El paradigma republicano muestra la necesidad de contar con lugares donde la ciudadanía pueda reunirse para adquirir conocimientos, mismos que le permitan participar plenamente con libertad en torno a los asuntos comunes. Entonces el espacio público bibliotecario, destinado para todos los grupos que conforman la sociedad, la comunidad o el pueblo, es uno de los sitios donde florece o puede brotar y prosperar la libertad política 
inherente a la práctica de la lectura pública, como fundamento que orienta y caracteriza el espíritu republicano, es decir, como "consigna republicana por excelencia" (ÁLVAREZ, 2005, p. 13). Debido a esto, las bibliotecas públicas tienden a ser valoradas como aquellas instituciones que fomentan y estimulan la discusión pública en relación con los intereses comunes. Si es que estas bibliotecas no solamente son la piedra angular de la democracia (KRANICH, 2001, p. 83), sino también la piedra base de la república. Desde esta óptica, el bibliotecario público-político personifica tanto la democracia como la república.

Para quien se responsabiliza como bibliotecario político tampoco debe ser indiferente con el asunto de los derechos humanos, es decir, "[...] el bibliotecario debe ser un profesional que no se calla ante las injusticias, la opresión y los derechos del ciudadano en todas las áreas de su existencia, pero especialmente en lo que se refiere al derecho básico y constitucional a la información" (CORRÊA y PRADO, 2018, p. 116). Si el derecho a la información se concibe como un derecho que otorga la Constitución política del Estado, entonces la práctica política de la libertad de acceso a la información compete al bibliotecario en su calidad de ente político, y de la cual se deriva el derecho concerniente a la libertad de leer. Considerando este propósito, es tiempo ya de reconocer a las bibliotecas públicas como un derecho político y no únicamente social y cultural (MENESES, 2017, p. 69-71). Significa entonces que una vertiente de la filosofía política, inherente a la biblioteconomía pública, se puede cimentar, en el siglo que transcurre, en la teoría y práctica de los derechos humanos, los cuales están estrechamente vinculados con el tema de los grupos vulnerables y la democracia (SAHUI, 2018). Esfera cognitiva en la que también pueden entrar en juego los servicios bibliotecarios con percepción político-democrática en contextos claros de vulnerabilidad social (MENESES, 2008a, p. 55-56).

Si tomamos en cuenta que: "La información política es foco del proceso decisorio y en este sentido la Biblioteconomía asume un papel importante, como facilitadora del proceso de transferencia de la información, de promotora de la divulgación del conocimiento" (BUFREM, 1985, p. 120), entonces el concepto de biblioteconomía política adquiere particular relevancia en el mundo práctico del bibliotecario político. Perspectiva teórico-práctica que no puede ni debe seguir pasando inadvertida en el contexto de la academia, es decir, en donde se forman las presentes y futuras generaciones de profesionales de la biblioteconomía y/o bibliotecología.

Ciertamente los bibliotecarios políticos "participan en debates, se afilian en asociaciones y sindicatos, asumen direcciones de consejos, realizan proyectos sociales y se involucran en la política partidista. Saben que, incluso a pasos lentos, es necesario seguir luchando" (BRAYNER y MATTOS, 2018, p. 190). Son quienes se involucran, mediante su labor bibliotecaria, en la política de manera indirecta y directa para influir en el proceso político y en sistema político para así ayudar a lograr el bien común para todos, colaborando de manera resuelta en el desarrollo de 
la justicia social. De tal manera que en el entorno del estatus político de la biblioteca pública, "el bibliotecario [...] es el político estratégico en casi todos los casos" (GARCEAU, 1949, p. 113).

Con el fin de exponer algunos ejemplos de lo que en la práctica es un bibliotecario político, se recurre a dos personajes de la biblioteconomía estadounidense. El primero es el referente a la vida y obra de Rebecca Browning Rankin (1887-1965), quien es considerada, en el contexto profesional de la ciudad de New York y en el mejor sentido de la palabra, como una verdadera bibliotecaria política. El título de libro: A true politician: Rebeca Browning Rankin, municipal reference librarian of the City of New York, 1920.1952, es muy sugerente al respecto (SEAVER, 2004). El quehacer comprometido que desarrolló ella es una muestra histórica de la importancia que puede adquirir el trabajo del personal bibliotecario público con perspectiva política; es un modelo de cómo puede figurar políticamente un/a profesional de la biblioteca pública. El segundo ejemplo es Zoia Markovna Horn (1918-2014), como tenaz activista por la paz, incansable defensora por la libertad intelectual, oponente a la polémica Ley Patriota y contraria al cobro de tarifas en las bibliotecas públicas, es un personaje relevante en la esfera política que nos ocupa. Así, Horn ha pasado a la historia como la primera bibliotecaria de los Estados Unidos que fue encarcelada por defender sus principios y valores políticos en su condición de ciudadana profesional de la biblioteconomía en tiempos en que las libertades civiles en ese país enfrentaban severa crisis sociales, políticas y culturales. Su libro Zoia!: memoirs of Zoia Horn, battler for people's right to know (HORN, 1995) es el mejor testimonio de primera mano que recoge su pensar y obrar con evidente praxis política.

Naturalmente hay otras celebridades en el campo de la biblioteconomía política estadounidense, solo por mencionar cabe recordar a Ruth Winifred Brown (1891-1975), defensora de la igualdad racial y bibliotecaria de la Biblioteca Pública de Bartlesville, Oklahoma, quien fue despedida de su trabajo después de treinta años de servicio ejemplar, aparentemente porque había circulado materiales subversivos (ROBBINS, 2000);Elonnie Junius Josey (19242009), bibliotecario afroamericano y editor del libro Libraries in the political process (Josey, 1980);y Eric Edward Moon (1923-2016), editor en jefe durante nueve años del connotado Library Journal y quien puso sobre la mesa de debate público el caso de las bibliotecas estadounidenses que segregaban racialmente a la comunidad de lectores y usuarios (KISTER, 2002, 405)entre otras célebres personalidades. En otras latitudes, como en Iberoamérica, es posible que existan colegas que también figuren en este marco. Asunto que podría ser tema de otro trabajo, basándose en la historia de vida como uno de los métodos de investigación.

\section{Conclusión}


En torno a la relación «bibliotecología y política», observamos que se han desarrollado apreciaciones teóricas en la literatura especializada, pero hay una gran omisión sobre este asunto en el campo de la educación inherente a esta disciplina. Este inconveniente, entre el discurso y la docencia, no ha permitido que la política, teórica y práctica, sea considerada como un tema preponderante en la gestión y administración de los sistemas bibliotecarios y de información, particularmente los constituidos por la diversidad de bibliotecas públicas que funcionan como instituciones de bien común.

Si existe un tipo de biblioteca, mediante la cual pueda explicarse el influjo político que tiene el personal bibliotecario en el entramado de un Estado democrático y republicano, ese es el referente al de la biblioteca pública, la dirigida a toda la comunidad. Por esto, los diversos grupos que constituyen el gremio bibliotecario deben estudiar y analizar el corpus de la literatura en materia de biblioteconomía pública (public librarianship) para comprender mejor la noción de biblioteconomía política (political librarianship), cuyo discurso científico ha comenzado a construirse desde las ópticas de la bibliotecología, la biblioteconomía y la ciencia de la información. Discurso que ha comenzado con firmeza a echar abajo los argumentos que defienden aún la actitud de continuar cultivando una biblioteconomía despolitizada. Aislar o alejar el carácter político de las bibliotecas públicas, es tratar de evitar la naturaleza política de las cosas, las acciones y los pensamientos de los bibliotecarios al servicio de la sociedad. En este sentido, es necesario distinguir con claridad, por un lado, la participación de este personal en los asuntos públicos, en las políticas públicas; y por el otro, la administración de los acervos y recursos al servicio del interés público con el objetivo de politizar la función social de las bibliotecas públicas.

Es evidente que el trabajo del bibliotecario público ocurre en el mundo de la política y de lo político. Consecuentemente, es menester considerar que los diferentes protagonistas de la bibliotecología y/o biblioteconomía actúen en la formación de personal bibliotecario más y mejor politizado. Es decir, proporcionando orientación y contenido político a actos, pensamientos y posturas de quienes trabajan en las bibliotecas destinadas para todos los grupos y comunidades que conforman la sociedad. Desarrollar y consolidar la formación de una ciudadanía consciente, informada, ilustrada, crítica, comprometida y participativa, en los contextos democráticos y republicanos, no es solamente responsabilidad política del personal docente de las escuelas, sino también del personal de las bibliotecas públicas en general y de las bibliotecas escolares en particular. Si la democracia exige de una ciudadanía informada y con pensamiento crítico, entonces requiere también de bibliotecarios públicos que desarrollen colecciones para promover habilidades de uso de los diversos recursos y fuentes de información, 
a tal punto de producir actos de búsqueda autónoma de libros, revistas y periódicos entre sus comunidades de lectores y usuarios.

Para que el bibliotecario público logre alcanzar el estatus de bibliotecario político, su trabajo debe llevarlo a cabo inspirándose y basándose en los valores y principios de la democracia. Así que este profesional tiene el compromiso de demostrar que las bibliotecas públicas son relevantes y pertinentes en el contexto de una vida democrática, en la que confluye los desafíos de gestionar servicios bibliotecarios y de información para la diversidad de grupos vulnerables. Histórica y teóricamente este tipo de centros bibliotecarios son reconocidos en la literatura especializada como instituciones democráticas, en tanto tienen la misión políticocultural de apoyar el proceso de formación de ciudadanos educados, informados e ilustrados. Ciudadanía indispensable para el buen funcionamiento de la república como sistema de gobierno. En este sentido los sistemas de bibliotecas públicas, conformados en redes alrededor del mundo, adquieren un importante potencial político y un elevado valor cívico en la esfera de la información a disposición de la diversidad cultural de naciones, pueblos, comunidades, grupos e individuos.

En concordancia con lo escrito, las bibliotecas públicas y sus bibliotecarios no pueden aislarse del espacio público de la política, porque en el contexto político de un régimen democrático este tipo de instituciones figuran en la órbita política del Estado, constituido en república. Así, el marco de la dimensión política de las instituciones bibliotecarias, destinadas al uso democrático de todos los grupos sociales, es el orden político del Estado republicano. Entorno en el que estas instalaciones de servicio público forman parte de los elementos del ejercicio de la política, por ende, del bien común. En otras palabras, las bibliotecas públicas funcionan en y para el régimen político de la democracia; así como en y con el sistema político de la república. Estos son los contextos en que puede y debe desarrollarse el bibliotecario político, quien tiene que figurar como un profesional de la información impregnado de compromiso para asistir a la comunidad, imbuido de responsabilidad de servicio reflexivo y activo. Misión histórica centrada en la praxis política bibliotecaria concerniente a colaborar con la transformación del mundo, a contribuir para lograr un mundo mejor. El actuar del bibliotecario público como bibliotecario político en el mundo implica ir más allá de la esfera de la biblioteconomía tradicional; significa estar abierto al mundo de la política y de lo político para conocer y saber los asuntos que se plantean en el contexto de la sociedad y el Estado. Desde esta óptica ya no es viable que el personal de la biblioteca pública se mantenga al margen de la política, ni la política apartada del radio de acción de esta institución bibliotecaria.

El trabajo del bibliotecario público no consiste simplemente en una serie de actividades profesionales sin sentido político, pues él no es un ser abstracto, es un profesional que no debe 
ni puede seguir siendo indiferente a lo que sucede en relación con el sistema y el proceso políticos. Por el contrario, como afirman los diferentes autores citados en el presente discurso, el personal de las bibliotecas públicas se halla cotidianamente inmerso en el mundo de la política que caracteriza a la sociedad y al Estado. $Y$ es así porque el tipo de biblioteca que hace funcionar este personal es, en primera instancia, un servicio público regulado por el Estado y gestionado por el gobierno a través del aparato denominado Administración Pública. En este sentido, las instituciones bibliotecarias destinadas para toda la sociedad son reflejo de las políticas sociales y culturales. Consecuentemente el actuar de los bibliotecarios al servicio de la comunidad o del pueblo no está desprovisto de contenido político. Desde esta perspectiva, las bibliotecas públicas son algunas de las instituciones más emblemáticas tanto de la democracia como de la república. Es decir, son paradigma de la democratización política en materia de acceso a la información bibliográfica organizada; y modelo del espacio público para generar civilidad y apoyar el importante proceso que infiere construcción ciudadana.

Con base en lo expresado, la dimensión política de las bibliotecas públicas se genera y entreteje a través de dos tradiciones políticas: la democrática y la republicana. Recordemos que el nacimiento de estas bibliotecas comienza en el mundo antiguo de las civilizaciones grecolatinas, es decir, en Grecia y Roma. Culturas clásicas en las que se fundan la democracia y la república respetivamente como formas de vida, gobierno y Estado. Y las bibliotecas públicas en el mundo moderno se originarían, durante el siglo XIX, también en los entornos de estas formaciones políticas, propias de la tradición cultural occidental. Durante el siglo XX el quehacer de las bibliotecas públicas siguió estando en el núcleo de los proyectos políticos, sociales y culturales de la democracia y de la república, construyendo en torno a ellas una imagen institucional valiosa para la conformación y consolidación de una ciudadanía ilustrada a través de la lectura de libros, revistas y periódicos. Por consiguiente, el bibliotecario público en el siglo XXI se puede y debe instituir como un bibliotecario político en los ejes de la democracia republicana y/o en la república democrática. Hoy en día, la democracia y la república son todavía los modelos de sociedades políticas en las que se funda, estimula y aviva el quehacer de este tipo de instituciones bibliotecarias. De manera que el perfil del bibliotecario público, como protagonista político en estos escenarios, se puede desgranar en dos categorías congruentes, subsecuentes y sincronizadas: el bibliotecario democrático y/o el bibliotecario republicano.

\section{Referencias}

ALBORNOZ DELGADO, C.; MIR ARAYA, I.; OLIVERA INFANTE, C. Bibliotecas públicas de Chile y compromiso político. Serie Bibliotecología y Gestión de Información, n. 97, p. 1-31, 2016. 
ÁLVAREZ ZAPATA, D. Perspectiva cultural, educativa y política de la biblioteca pública. Leitura: Teoria \& Prática, v. 24, n. 46, p. 11-23, 2006.

ÁLVAREZ ZAPATA, D. Una mirada a los estudios de comportamiento lector en las bibliotecas públicas en América Latina. México: Consejo Nacional para la cultura y las Artes, 2005, p. 9-40.

ARISTÓTELES. Política. 2a ed. México: Universidad Nacional Autónoma de México, 2000.

BECKERMAN, E. Politics and the American public library: creating political support for library goals. Lanham, MD: Scarecrow Press, 1996.

BERASA, V. E. Ideología y bibliotecología: algunas reflexiones sobre neutralidad, ética, política y militancia. Fuentes: Revista de la Biblioteca y Archivo Histórico de la Asamblea Legislativa Plurinacional.v. 15, n. 45, 6-19, 2016.

BERRY, J. N. Politics \& Libraries: every great librarian is a politician. Library Journal. v. 139, n. 14, p. 10, 2014.

BIRDSALL, W. F. A political economy of librarianship? Progressive Librarian, n. 88, p. 1-8, 2001.

BIRDSALL, W. F. Uma economia política da biblioteconomía? Perspectiva em Ciência da Informação,v. 10, n. 1, p. 86-93, 2005.

BORNACELLY CASTRO, J. A., QUINTERO CASTRO, N., CUARTAS CELIS, D. Política pública en bibliotecas: reflexiones sobre su evaluación. Medellín: Editorial Universidad de Antioquia, 2014.

BRAYNER, C. J. O. S., MATTOS, M. C. C. M. O bibliotecário (in)visível: o poder e as narrativas na política nacional do livro. Em SPUDEIT, D.; PEREIRA, D.; LOBÃO, I.; DAVID, I. (Orgs.). Formação e atuação política na biblioteconomia. São Paulo: ABECIN Editora, 2018, p. 189-205.

BUFREM, L. S. Fundamentos sociais e políticos da biblioteconomia. Educar: Revista do Sector de Educação da Universidade Federal do Paraná, v. 4, n.1, p. 108-122,1985.

BYRNE, A. The politics of promoting freedom of information and expression in international librarianship. Lanham, MD: Scarecrow Press, 2007.

CERRONI, U. Política: método, teorías, procesos, sujetos, instituciones y categorías. 2a ed. México: Siglo Veintiuno editores, 1997.

CIVALLERO, E. La biblioteca como trinchera de resistencias, militancias, políticas y estantes con libros. Fuentes: Revista de la Biblioteca y Archivo Histórico de la Asamblea Legislativa Plurinacional, v. 15, n. 45, 65-72, 2016.

CONDE, S. L. La educación ciudadana: desafíos y huellas del camino andado. En: CASTRO, I. (coord.) Educación y ciudadanía: miradas múltiples. México: Universidad Nacional Autónoma de México, 2006, p. 81-111.

CORRÊA, E. C. D., PRADO, J. M. K. Hiperlinks subvertem hierarquias; atuação política do bibliotecário na socidade digital. Em SPUDEIT, D.; PEREIRA, D.; LOBÃO, I.; DAVID, I. (Org.). Formação e atuação política na biblioteconomia.São Paulo: ABECIN Editora, 2018. p. 107-123. 
CÔRTE, A. R. Bibliotecário: uma profissão politicamente correta. In: SPUDEIT, D.; PEREIRA, D.; LOBÃO, I.; DAVID, I. (Org.). Formação e atuação política na biblioteconomia. São Paulo: ABECIN Editora, 2018. p. 93-106.

D'ANGELO, E. Barbarians at the gates of the public library: how postmodern consumer capitalism threatens democracy civil education and the public good. Duluth, MN: Library Juice Press, 2006.

DITZION, Sidney Herbert. Arsenals of a democratic culture, a social history of the American public library movement in New England and the middle states from 1850 to 1900. Chicago: American library association,1947.

DURRANI, S. Information \& liberation: writings the politics of information \& librarianship. Duluth, MN: Library Juice Press, 2008.

FLUSSER, V. Uma biblioteca verdadeiramente pública. Revista da Escola de Biblioteconomía da UFMG, v. 9, n. 2, p. 131-138, 1980.

FÚSTER, Y., LANGELÁN, C. La información y la lectura para presas políticas durante la dictadura militar en Uruguay. Revista Interamericana de Bibliotecología, v. 33, n. 1, p. 125-139, 2010.

GARCEAU, O. The public library in the political process. New York: Columbia University Press, 1949.

GARCÍA, J., SUTHERLAND, S. Directores de biblioteca pública en la arena política. Barcelona: Fundación Bertelsmann, 2001.

GONZÁLEZ URIBE, H. Teoría política. 9ạ ed. México: Editorial Porrúa, 1995.

GORMAN, M. Our enduring values: librarianship in the 21st century. Chicago: American Library Association, 2000.

HARRIS, S. The cultural politics of librarianship: imperialism or nationalism. Germany: Lap Lambert Academic Publishing, 2012.

HORN, Z. Zoia!: memoirs of Zoia Horn, battler for people's right to know. Jefferson, NC: McFarland, 1995.

JAEGER, P. T., GORHAM, U., BERTOT, J. C., SARIN, L. C. Public libraries, public policies, and political processes: serving and transforming communities in times of economic and political constraint. Lanham, MD: Rowman \& Littlefield, 2014.

JAEGER, P. T.; SARIN, L. C. All librarianship is political: educate accordingly. The Political Librarian, v. 2, n. 1, p. 17-27, 2016.

JARAMILLO, O., ÁLVAREZ ZAPATA, D., MONCADA, D. Políticas públicas para bibliotecas públicas: una propuesta de soluciones locales a problemas globales. Investigación Bibliotecológica, v.19, n. 39, p. 13-27, 2005.

JOSEY, E. J. (Ed.). Libraries in the political process. Phoenix, AZ: Oryx Press, 1980.

KISTER, K. F. Eric Moon: the life and library times. Jefferson, NC: McFarland, 2002. 
KRANICH, N. C. Libraries, the internet, and democracy. In: KRANICH, N. (Editor). Libraries \& democracy: the cornerstones of liberty. Chicago: American Library Association, 2001, p. 83-95.

LAMAS, T. A. As dimensões políticas da biblioteconomia no Brasil. Em SPUDEIT, D.; PEREIRA, D.; LOBÃO, I.; DAVID, I. (Org.). Formação e atuação política na biblioteconomia. São Paulo: ABECIN Editora, 2018, p. 23-53.

LOBÃO, I. S. L. O fazer político na biblioteconomia: atuação dos conselhos, sindicatos e associações de biblioteconomia no Brasil. Em SPUDEIT, D.; PEREIRA, D.; LOBÃO, I.; DAVID, I. (Org.). Formação e atuação política na biblioteconomia. São Paulo: ABECIN Editora, 2018. p. 157188.

MACHADO, E. C., JUNIOR, A. C. E, ACHILLES, D. A biblioteca pública no espaço público: estratégias de mobilizaçãocultural e atuação sócio-política do bibliotecário. Perspectivas em Ciência da Informação, v. 14, n. especial, p. 115-127, 2014.

MAGENDZO, A. Formación ciudadana. Bogotá, Colombia: Cooperativa Editorial Magisterio, 2004.

MARTINS, C. W. S., FERREIRA, M. M. Bibliotecária(o)s na política: perfil da(o)s professionais bibliotecária(o)s nas eleicoes mnicipais brasileiras de 2016. Em SPUDEIT, D.; PEREIRA, D.; LOBÃO, I.; DAVID, I. (Org.). Formação e atuação política na biblioteconomia. São Paulo: ABECIN Editora, 2018. p. 75-92

MATOSO, R. O contributo das bibliotecas públicas para a efetivação da democracia cultural. Em: SEQUEIROS, Paula; MEDEIROS, Nuno (Org.). Bibliotecas públicas, políticas culturais e leitura pública. CESCONTEXTO, n. 23, p. 11-34, 2018.

McCABE, R. B. Civic librarianship: renewing the social mission of the public library. Lanham, MD: Scarecrow Press, 2001.

MEDEIROS, A. L. Bibliotecas y cidadania. Sinais Sociais, v.4, n. 13, p. 10-45, 2010.

MENESES TELLO, F. Bibliotecas, información y golpe de Estado: teoría en el contexto relacionado con la crisis política en Honduras. Revista General de Información y Documentación, v. 21, p.187224, 2014.

MENESES TELLO, F. Bibliotecas, política y guerra: el paradigma bélico de la biblioteca pública. Anuario de Bibliotecología, Nueva Época, v. 1, n. 2, p. 53-87, 2013.

MENESES TELLO, F. Bibliotecas y democracia: el caso de la biblioteca pública en la construcción de una ciudadanía activa. Anales de Documentación: Revista de Biblioteconomía y Documentación, v. 11, 93-127, 2008.

MENESES TELLO, F. Bibliotecas y política: el paradigma político de la biblioteca pública. Anales de Documentación: Revista de Biblioteconomía y Documentación, v. 16, n. 2, p. 1-14, 2013 a.

MENESES TELLO, F. La dicotomía social y política del servicio de biblioteca: ¿usuarios o clientes? Revista Prefacio, v. 1, n. 1, 5-15, 2017.

MENESES TELLO, F. Las dimensiones social y política del bibliotecario público. En Memoria del Foro Nacional de Profesionales de la Información "Prospectiva de la profesión bibliotecaria: 
visiones y aproximaciones". México: Escuela Nacional de Biblioteconomía y Archivonomía, 2014. p. 194-207.

MENESES TELLO, F. Información y bibliotecas en torno a los derechos humanos. Revista Brasileira de Biblioteconomia e Documentação, v. 13, n. 2, p. 42-84, 2017.

MENESES TELLO, F. Servicios bibliotecarios para grupos vulnerables: la perspectiva en las directrices de la IFLA y otras asociaciones. Informação \& Sociedade: Estudos, v. 18, n. 1, p. 4566, 2008.

MERKLEN, D. Bibliotecas en llamas: cuando las clases populares cuestionan la sociología y la política. Los Polvorines, Argentina: Universidad Nacional de General Sarmiento, 2016.

MERKLEN, D. Is the library a political institution? French libraries today and social conflict between democratie and république. Library Trends, v. 65, n. 2, p. 143-153, 2016a.

OPORTO ORDOÑEZ, L. Las bibliotecas políticas de los mineros revolucionarios de Bolivia. Fuentes: Revista de la Biblioteca y Archivo Histórico de la Asamblea Legislativa Plurinacional, v. 15, n. 45, p. 43-52, 2016.

PARADA, A E. Tras las huellas de la biblioteca pública y su trama política: una incursión desde la Argentina. Fuentes: Revista de la Biblioteca y Archivo Histórico de la Asamblea Legislativa Plurinacional, v. 15, n. 45, p. 27-42, 2016.

PHILLIPS, A. Género y teoría democrática. México: Universidad Nacional Autónoma de México: Instituto de Investigaciones Sociales: Programa Universitario de Estudios de Género, 1996.

QUIROGA, N. Lectura y política: Ios lectores de la Biblioteca Popular Juventino Moderna de Mar de la Plata (fines de los años treinta y principio de los cuarenta). Anuario IEHS, v. 18, p. 449-474, 2003.

RABOTNIKOF, N. El espíritu republicano moderno y las acechanzas de la cuestión social. En: VELASCO GÓMEZ A.; DI CASTRO, E.; BERTOMEU, M. J. (Coord.) La vigencia del republicanismo. México: Facultad de Filosofía y Letras, Universidad Nacional Autónoma de México, 2006, p. 187207.

ROBBINS, L. S. The dismissal of miss Ruth Brown; civil rights, censorship and the American library. Oklahoma: University of Oklahoma Press, 2000.

ROBBINS-CARTER, J. Political science: utility for research in librarianship. Library Trends. v. 32, n. 4, p. 425-439, 1984.

RUBIN, R. E. Foundations of library and information science. New York: Neal-Schuman, 2010.

SAHUÍ MALDONADO, A. Derechos humanos, grupos vulnerables y democracia. Ciudad de México: Editorial Fontamara, 2018.

SÁNCHEZ VÁZQUEZ, A. La filosofía de la praxis. En: QUESADA, F. (Editor). Filosofía política l: ideas políticas y movimientos sociales. Madrid: Editorial Trotta, 1997, p. 17-35.

SANTOS, B. S. Reinventar la democracia: reinventar el Estado. La Habana: Instituto Cubano del Libro, Editorial José Martí, 2005. 
SEAVER, B W. A true politician: Rebeca Browning Rankin, municipal reference librarian of the City of New York, 1920.1952. Jefferson, NC: McFarland, 2004.

SHAVIT, D. Federal aid and state library agencies: federal policy implementation. Westport, Connecticut: Greenwood, 1985.

SHAVIT, D. The politics of public librarianship. New York: Greenwood, 1986.

SILVA, G. F. M. Por uma biblioteconomia progressista: menos técnicos, mais agentes de transformação social. Em Formação e atuação política na biblioteconomia. São Paulo: ABECIN Editora, 2018.p. 209-223.

SILVA, J. L. C.; SILVA, R L. Biblioteca, luta de classes e o posicionamiento da biblioteconomia brasileira: algumas considerações. Em Questão, v. 16, n. 2, p. 203-217, 2010.

SMITH, K. (Ed.). Preface. En: The politics of libraries and librarianship: challenges and realities Oxford, England: Chandos, 2009.p. xxix-xxx.

SOSA PLATA, J. A. Información política y perspectiva estratégica. En: T. Miklos (coord.). Las decisiones políticas: de la planeación a la acción. México: Siglo XXI Editores, 2001, p. 277-320

SPUDEIT, D., PEREIRA, D., LOBÃO, I. , DAVID, J. (Org.). Formação e atuação política na biblioteconomia. São Paulo: ABECIN Editora, 2018.

SPUDIET, D., PEREIRA, D., LOBÃO, I. S. L. O fazer político na biblioteconomia: atuação dos conselhos, sindicatos e associações de biblioteconomia no Brasil. In: SPUDEIT, D.; PEREIRA, D.; LOBÃO, I.; DAVID, I. (Org.). Formação e atuação política na biblioteconomia. São Paulo: ABECIN Editora, 2018, p. 157-188.

SPUDEIT, D., MORAES, M. B., CORRÊA,E. D. Formação política do bibliotecário no Brasil. Revista Brasileira de Educação em Ciência da Informação, v. 3, n. 1, p. 24-46, 2016.

TARGINO, M. G. Praxis bibliotecária. Informação \& Sociedade: Estudos, v. 7, n. 1, p.26-33, 1997.

TAVARES, A. A. S. O bibliotecário no Norte do Brasil: breve relato acerca de ações e actuações políticas. In: SPUDEIT, D.; PEREIRA, D.; LOBÃO, I.; DAVID, I. (Org.). Formação e atuação política na biblioteconomia. São Paulo: ABECIN Editora, 2018. p. 141-156.

THOMPSON, J. A history of the principles of librarianship. London: Clive Bingley, 1977.

VITZANSKY, W. Libraries and politics - Danish reflections and examples. In: SMITH, K. (Editor). The politics of libraries and librarianship: challenges and realities. Oxford, England: Chandos, 2009. p. 117-127.

YURÉN, T. Ciudadanía y educación: ideales, dilemas y posibilidades de la formación ético-política. México: Universidad Autónoma del Estado de Morelos: Juan Pablos Editor, 2013. 